tion falls below 70 or 80 the lymph is defective, and the use of a stronger lymph will produce success in the case of some of the previous failures.

\section{A Correction.}

DRS. ROWLAND THURNAM and NEvilLE GWYNN (Nordrach-upon-Mendip, Blagdon R.S.O,, Somerset) write: A paragraph on page 247 of the BRITTSH MEDICAL JOURNA
which is also regrettable.

We have not named our sanatorium "Nordrach-in-Mendip," but Nordrach-upon-Mendip, following the custom of the countryside in naming places here - that is, "Charterhouse-upon-Mendip," "Leighupon-Mendip," ete. We have, furthermore, named our sanatorium after the one where we were both cured, since, with so many so-called open-
air cures and pseudo-sanatoria springing up at the present time, we air cures and pseudo-sanatoria springing up at the present time, we Nordrach-Colonie, which are at once so well known and so successful.

S. S. C. Wr Headache caused by ERYthrol Tetranitrate.

note by "R.A.M.C." on this subject. I have prescribed it in two cases of women suffering from high arterial tension during the menopause, in both of which it gave rise to severe headache; both patients characterised it as the worst headache they had ever experienced, and one of the ladies has suffered from migraine all her life. Mentioning this to a medical neighbour not long since, he told me of a case he had prescribed it in for angina, in which it had the same effect. On the other hand my
father, who has taken half a grain daily for over a year for anginal attack with great benefit, has never had the least symptom of headache. $I$ may add that in both my cases nitro-glycerine is taken without any unpleasant symptoms except the usual fulness and throbbing in the
head.

INTRACEREBRAL INJECTION OF ANTTTOXIN,
DR. JAMES! WATSON (Nottingham) writes: Dr. Semple;

BRITISH MEDICA (Nottingham) writes: Dr. Semple's paper in the write only to suggest a simplification 7 th is very interesting, and 1 injection. For the past thirty or forty years in certain districts it has been common for sheep farmers and shepherds to empty and remove cœnurus cysts from the brains of their sheep. They use an apparatus consisting essentially of a simple trocar-like drill (having a pyramidal point and a collar to prevent too deep penetration) and a trocar and cannula. They push the drill through the skin, etce, down to the bone. and with a few turns of the wrist put it through the bone till stopped by the collar. They then insert the trocar and cannula, which is very
slightly smaller than the drill. I need not complete the description of this operation, but would suggest that Dr. Semple will find a simple method like this quite sufficient. The risk of sepsis will certainly not be increased, and it will save $(a)$ the incision, $(b)$ the stitches, and $(c)$ the
scar.

EXEMPTIONS FROM VACCINATION.

MAGNA EST VERITAS writes: If, as I take it, the protective value of vaccination remains unassailed by the worst that a Royal Commission could do, the only possible argument against compulsion is the one that the risk to the individual was of a kind sufficient to outweigh the safety conferred on the community, or that this safety could be as efficiently, or almost as efficiently, secured by isolation, notification, and general sanitation. In contrasting the value of vaccination with these substitutes for it-even if much more perfect than they yet are, or soon likely to be-we need only consider what it would mean to us if in our crusade against tuberculosis or our fight with malaria we had a weapon like vaccination. What would that not mean in lives, and money, and sense of security at home and in our colonies! The argument, then, against this slight "operation " reduces itself to an assertion that it is on all fours with other surgical operations which, though to save life, may not be done without consent, or that its riskiness forbids its compulsion. The former of these mas be ignored. since it takes no account of the risk to the community. With the latter, as already indicated, we can now deal, but it must be remembered that until lately there has been much in it, in fact more than our opponents or we ourselves were aware of. Every practitioner must admit that from time to time septic inoculation or infection has accompanied or followed vaccination. The fact that by research we can now with glycerine, etc., separate the essential from the non-essential organisms does not do away with the fact that hitherto children have been compulsorily inoculated with we know not what. This, perhaps, ought to make us
patient, and even "suffer fools gladly," until we are sure of our methods and remedy, and be prepared, meanwhile, for emergencies.

Erythematous Rash Produced by Small Doses of Quinine.

DR. A. ST.LAWRENCE-BURKE (District Medical Officer Wolverhampton writes: The following remarkable susceptibility to the influence of quinine may prove interesting: On December 26th, r898, at 9.30 P.M., I was called to see a woman, aged $3 \mathrm{x}$, whom I had attended at her confine-
ment the day previous. I found her suffering from a severe ment the day previous. I found her suffering from a severe rigor. I felt alarmed, especially as everything was right when I saw her the same morning, and her temperature quite normal. I found the temperature had gone up to $17^{\circ}$; the tongue was very dry, and every symptom, of fever present. The patient remarked that she had a similar "shiver" some two years before, when she was last confined. I gave directions
what was to be done, and made up a mixture of quinin sulph what was to be done, and made up a mixture of quinin. sulph. gr. 40 ,
acid sulphurici dil. 3 jss, aqua 3 viij. Two tablespoonfuls every third hour.

Next morning, December 27 th, I was suprised to find my patient completely covered with an erythematous rash very like scarlatina; all the tiver feverish symptoms liad disappeared, and she seemed comparatively easy. Knowing that quinine in large quantities produced a rash very rare, I thought I should stop the mix ture, and, as only half had been taken, watch the result. On the following morning, December 28 th everything had disappeared, and the woman made an uninterrupted recovery. In this case I am inclined to think that the rash was proas if the patient was very susceptible to the drug.
LETTERS, COMMUNIOATIONS, BTC., have been received from:

(A) Dr. W. Alexander, Portobello; Messrs. Arnold and Sons, London; Ajax: Dr. J. W. Anderson. Eastbourne; Professor T. Clifford Allbutt, Cambridge; Mr. R. Anderson,
Bury St. Edmunds; M. J. Adam. Hamilton; Mr. B. Atkinson. Olifton; Alph ; ; A. B. O. (B) Messrs. William Blackwood, and Sons, London; Dr. A. E. Brindley, Bury ; Dr. G. T. Meatson, Glasgow: Mr. A. Bird, Dudley; Mr. H. T. Butlin. London; H. L. Barnard, Ballantyne, Edinburgh; Dr. J. B. Brierley, Manchester; Mr. G. P. Bate, London; Dr. A. Bronner, Bradford; Dr. F. M. Burnett, sevenoaks; Mr. L. A. Bidwell, London. (C) Messrs. Clayton, Jowett, and Ward, Blackburn; Mrs. J. Coats, Glasgow; A. Croll, M.B.
Dudley; Correspondent; Dr. A. E. Cooper, London; C.; Dr. W. A. Carline, Lincoln; Mr. C. Clay, Salisbury; Mr. R. Oreasy, Windlesham ; Mr. G. B. Coleman, London. (D) Dubious; "Daily Graphic," Editor of the, London: Dr. A. T. Davies, London. (E) Dr. C. Ewart, London; Mr. E. S. B. Eames. Bury St. Edmunds; W. Edmunds, M.B., London; Mr. A. Eddowes, Loughborough. (F) Mr. W. T. Freeman, Reading; Mr.
W. E. Fairweather, Dudley; A. G. Prancis, M.B., Hull; A. H. Frere, M.B., Stradbroke W. E. Fairweather, Dudley; A. G. Francis, M. B., Hull; A. H. Frere, M.B., Stradbroke
Mr. F. C. FitzGerald, Cork; Mr. F. A. Field, London; Dr. W. F. Farquharson, Carlisle. (G) Dr. J. F. Goodhart, London; Dr. L. G. Guthrie, London; Dr. M. Greenwood, London ; Mr. W. C. Gent, Bristol; Mr. H. R. Greene, Belvedere: Mr. J. W. Gill, Halloway, London ; Human Lymph; Mr. J. Hutchinson, London; Mr. E. M. Hassard, Hoddesdon; Mr. A. H. Hardcastle, Hunslet; Dr. T. B. Hyslop, London; Mr. J. Harper, London; Dr. J. Hill, Renfrew; Mr. W. H. Hall, Frant. (I) Inquiro; Inquirer. (J) Mr.

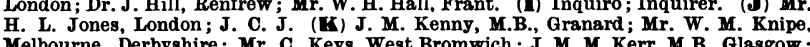
Melbourne, Derbyshire; Mr. C. Keys, West Bromwich; J. M. M. Kerr, M.B., Glasgow; Messrs. Krohne and Sesemann, London : Mr. A. F. A. King, Washington: Kidderminster L.R.C.P.Lond.; Dr. A. W. W. Lea, Manchester; Mr. J. D. Lawrie, Birmingham; Liverpool Medical Institution, Secretary of, Liverpool; Dr. G. A. Leon, Sidmouth. (M) Member B.M.A.; Mesmer; Medicus ; Mr. J. McKay, Belfast; M.R.C.S.Eng., L.S.A.; M. F. C. Melhado, London; Dr. W. MacGill, Denton; Dr. D. T. Masson, Edinburgh; C. F. G. Mummery, London: Member X.; Member; B. G. A. Moynihan, M. B., Leeds; Mr. A.

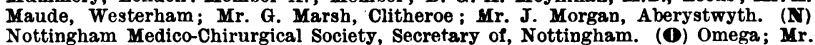
Nottingham Medico-Chirurgical Society, Secretary of, Nottingham. (O) Omega; Mr.
C. R. Owen, Rushden; Dr. I. Owen, London; Old Member. (P) Public Vaccinator; Dr. c. Pollard, Worcester; Mr. J. W. Plaxton, Kingston, W.I.; P.V.; H. J. Paterson, M.B., London; Practical; Mr. J. C. S. Pearson, London: Mr. G. Packer, Clifton; Dr. G. C. S. Perkins, London; P.V. for last 29 Years; Mr. W. F. Pike, London. (R) Mr. E. J. Reid, London; Dr. A. Roberts, Harrogate; Dr. T. H. Redwood. Rhymney; Dr. H. B. Robinson, pool; Dr. H. G. Smeeth, Stockport; Mr. A. Sanderson, Douglas; Lady Henry Somerset. Shaw-Mackenzie, London; Mr. S. Snell, Sheffeld ; Spes; Dr. J. E. Squire, London; S. H. (T) Dr. H. Tilley, London; Mr. L. Tait, Lland udno; Mr. A. Teevan, Ballarat; A. J. Tonkin, M.B., Manchester; B. Tonge, M.B., Millbrook. (U) University Graduate. (W) Dr. D. Walsh, London; Dr. T. J. Wood, Bradford; Dr. S. West, London; Mr. R. H. Molstenholme, Salford; Dr. A. T. T. Wise, Montreux; F. Wyatt-Smith, M.B., Reigate; Mr. N. I. Wright, Marpen, ; W. W. Wagstaffe, M.B., Sevenoaks; Dr. F. Willocks,
London; Dr. J. W. Watson. Limavady : Dr. J. S. Warrack, Aberdeen; W. Y. M.; Mr. B. Williams, Mold. (Y) Mr. M. T. Yarr, London; etc.

BOOKS, Etc., RECEIVED.

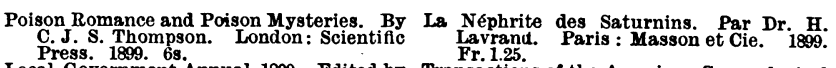

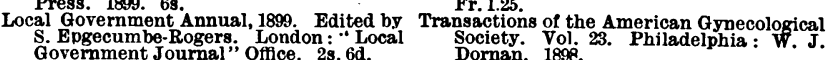

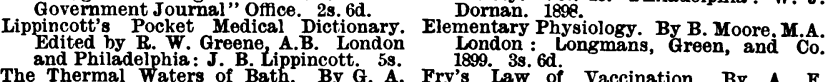

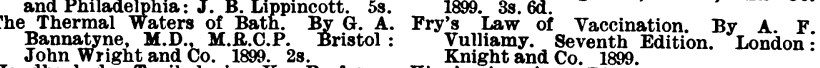

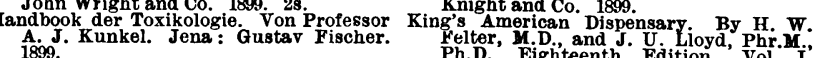

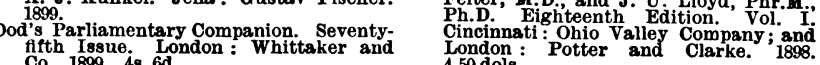

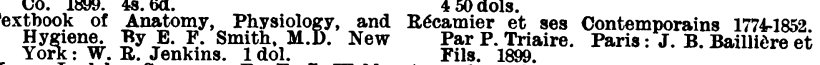

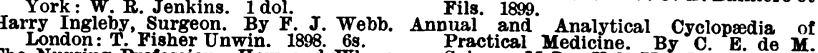

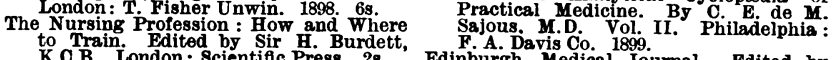

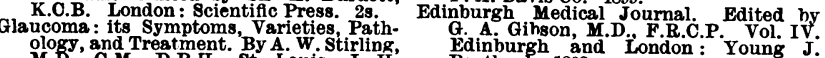

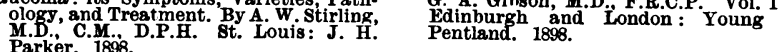

** In forwarding books the publishers are requested to state the selling prices.

SCAXE of Charges for abVERTISEMENTS IN ThE BRITISH MEDICAI JOURNAT.

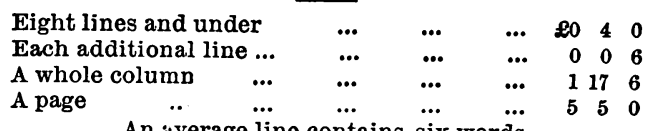

An average line contains six words.
Advertisements should be delivered, addressed to the Manager, at the Office, not later than first post on Wednesday morning preceding publica. tion; and if not paid for at the time, should be accompanied by a reference. Post-Office Orders should be made payable to the British Medical Association at the General Post-Ofince, London. Small amounts may be paid in postage-stamps.

N.B.-It is against the rules of the Pest Office to receive letters at Postes Restantes addressed either in initials or numbers. 